\title{
AVALIAÇÃo dAS CONDIÇÕES DE AERAÇÃO DO PRÉ- INÓCULO UTILIZADO NO CULTIVO DE BACTÉRIAS ÁCIDO LÁTICAS (BAL) EM MEIO LÍQUIDO
}

\section{EVALUATION OF PRE-INOCULAR AERATION CONDITIONS USED IN THE CULTIVATION OF LACTICAL ACID BACTERIA IN LIQUID MEDIUM}

\author{
S. A. C. A. .SÁ ${ }^{1}$, S. P. O. JÚNIOR ${ }^{1}$, M. T. DORES ${ }^{1}$, L. E. VISÔTTO ${ }^{2}$, C. R. SILVA ${ }^{1}$ \\ ${ }^{1}$ Instituto de Ciências Agrárias. Universidade Federal de Viçosa - Campus Rio Paranaíba \\ ${ }^{2}$ Instituto de Ciências Biológicas e da Saúde. Universidade Federal de Viçosa - Campus Rio \\ Paranaíba \\ E-mail: samara.sa@ufv.br
}

article info

Article history:

Received 12 May 2017

Accepted 3 August 2017

Available online 20 September 2017
PALAVRAS-CHAVE: Pré-inóculo; Bactérias ácido láticas; Acidificação. KEYWORDS: Pre-inoculum; Lactic acid bacteria; Acidification.

\begin{abstract}
RESUMO: As bactérias ácido láticas são de grande importância para a indústria alimentícia, pois promovem a acidificação do meio auxiliando na obtenção das características sensoriais de produtos fermentados e na conservação destes produtos por criar um meio inóspito para outros microrganismos. Este trabalho objetivou avaliar as condições de aeração para posterior padronização do pré-inóculo dos isolados de bactérias ácido láticas de queijo minas Minas artesanal. Foram realizados testes morfotinturial de gram e catalase para seleção dos isolados gram positivos, catalase negativos e no formato de cocos. Foram testadas diferentes proporções de aeração para obtenção do pré-inóculo e três concentrações iniciais com relação às proporções utilizadas. $O$ crescimento e acidificação dos isolados foram verificados á $32^{\circ} \mathrm{C}, 100 \mathrm{rpm}$, nos tempos de 12, 15 e 18 horas. Os isolados selecionados foram o ILC 4 e ILC23 apresentando características morfológicas desejadas. De acordo com análises realizadas no período médio de 18 horas e a uma concentração de 1\%, houve um maior crescimento de bactérias ácido láticas para o isolado ILC 4. Já para o isolado ILC 23, seu maior crescimento foi a uma concentração de $1 \%$ do isolado e a um tempo de 15 horas de cultivo. Quanto a acidificação, a partir das 12 horas iniciais observou-se um declínio nos valores de pH para ambos os isolados. Portanto a determinação do perfil de acidificação e crescimento de bactérias ácido láticas são essenciais, pois podem ser utilizadas como culturas iniciadoras para elaboração de produtos lácteos visando sua maior conservação $e$ obtenção de características sensoriais desejáveis.
\end{abstract}

\footnotetext{
ABSTRACT: Lactic acid bacteria are of great importance for the food industry, as they promote the acidification of the medium helping to obtain the sensorial characteristics of fermented products and the conservation of these products by creating an inhospitable environment for other microorganisms. This work aimed to evaluate the aeration conditions for subsequent standardization of the pre-inoculum of lactic acid bacterial isolates from Minas Gerais artisanal cheese. Morphotinturial tests of gram and catalase were performed for the selection of gram positive, catalase negative and coccole isolates. Different aeration ratios were tested to obtain the pre-inoculum and three initial concentrations with respect to the proportions used. The growth and acidification of the isolates were verified at $32^{\circ} \mathrm{C}, 100 \mathrm{rpm}$, at the times of 12, 15 and 18 hours. The selected isolates were the ILC 4 and ILC23 with the desired morphological characteristics. According to analyzes performed in the mean period of 18 hours and at a concentration of 1\%, there was a higher growth of lactic acid bacteria for the ILC 4 isolate. For the ILC 23 isolate, its greatest growth was at a concentration of
} 


\section{The Journal of Engineering and Exact Sciences - \\ JCEC \\ ISSN: 2527-1075}

$1 \%$ Of the isolate and at a time of 15 hours of cultivation. As for acidification, from the initial 12 hours a decline in $\mathrm{pH}$ values was observed for both isolates. Therefore, the determination of the acidification and growth profile of lactic acid bacteria are essential because they can be used as starter cultures for the elaboration of dairy products aiming at their greater conservation and obtaining desirable sensorial characteristics.

\section{INTRODUÇÃ̃}

As bactérias ácido láticas (BAL) são classificadas como gram positivas, catalase negativas e que se desenvolvem principalmente em condições anaeróbicas, com temperatura ótima em torno de 30 a $40^{\circ} \mathrm{C}$ e $\mathrm{pH}$ de 4,5 a 5,0 (LOPES, 2008).

Tais bactérias são essenciais no processo de produção de muitos queijos e bebidas lácteas fermentadas, visto que, a partir da fermentação da lactose ocorre a produção do ácido lático como produto principal de processos fermentativos promovendo a acidificação do meio (SILVA, 2011). Este ácido auxilia na conservação destes produtos, pois ao reduzir o pH do meio, cria-se um ambiente inóspito para o desenvolvimento de outros microrganismos, pois ocorre a inibição de esporos bacterianos promovendo a conservação de alimentos, como doces, bebidas alcoólicas produtos lácteos e etc (HUERTAS, 2010). Além de atuar na conservação, auxiliam também na obtenção das características sensoriais desejáveis nestes produtos. Diante do exposto, o presente trabalho teve como objetivo geral avaliar as condições de aeração e acidificação do pré-inóculo utilizado para o cultivo em meio líquido de BAL isoladas de queijos Minas artesanal da Região do Cerrado, MG.

\section{MATERIAL E MÉTODOS}

Teste de identificação por coloração de gram e catalase

Os isolados de BAL foram obtidos através do queijo Minas artesanal da região do Cerrado-MG. Os isolados foram submetidos à caracterização fenotípica utilizando o teste morfotinturial de gram e o teste de catalase.

Avaliação da porcentagem de aeração

Dois isolados, ILC4 e ILC23, em formato de cocos, gram positivos e catalase negativos foram selecionados e cultivados em meio líquido MRS. Foram testadas três proporções de aeração no preparo do pré-inóculo, sendo elas 1:5, 2:5 e 3:5 (volume do meio MRS : volume total do frasco erlenmeyer). Posteriormente foram avaliadas as concentrações iniciais de 1; 1,5 e $2 \%$ (v/v) do isolado em relação as proporções utilizadas. Estas soluções obtidas foram denominadas pré-inóculo e alíquotas foram coletadas nos tempos 12,15 e $18 \mathrm{~h}$ a $32^{\circ} \mathrm{C}$ e 100 rpm para posterior leitura da densidade óptica (D.O) a um comprimento de onda de $600 \mathrm{~nm}$.

Avaliação do perfil de $\mathrm{pH}$

Foram coletadas alíquotas nos tempos de 12, 15 e 18 h para medição do $\mathrm{pH}$ com auxílio de um pHmetro portátil (MS TECNOPON-MPA $210 \mathrm{P}$ pH portátil). 


\section{RESULTADOS E DISCUSSÃO}

As condições mais favoráveis para o preparo do pré-inóculo para o isolado ILC4 foram observadas ao utilizar a concentração de $1 \%$ do isolado por um tempo de $18 \mathrm{~h}$ de cultivo na proporção de 1:5 (Figura 1).

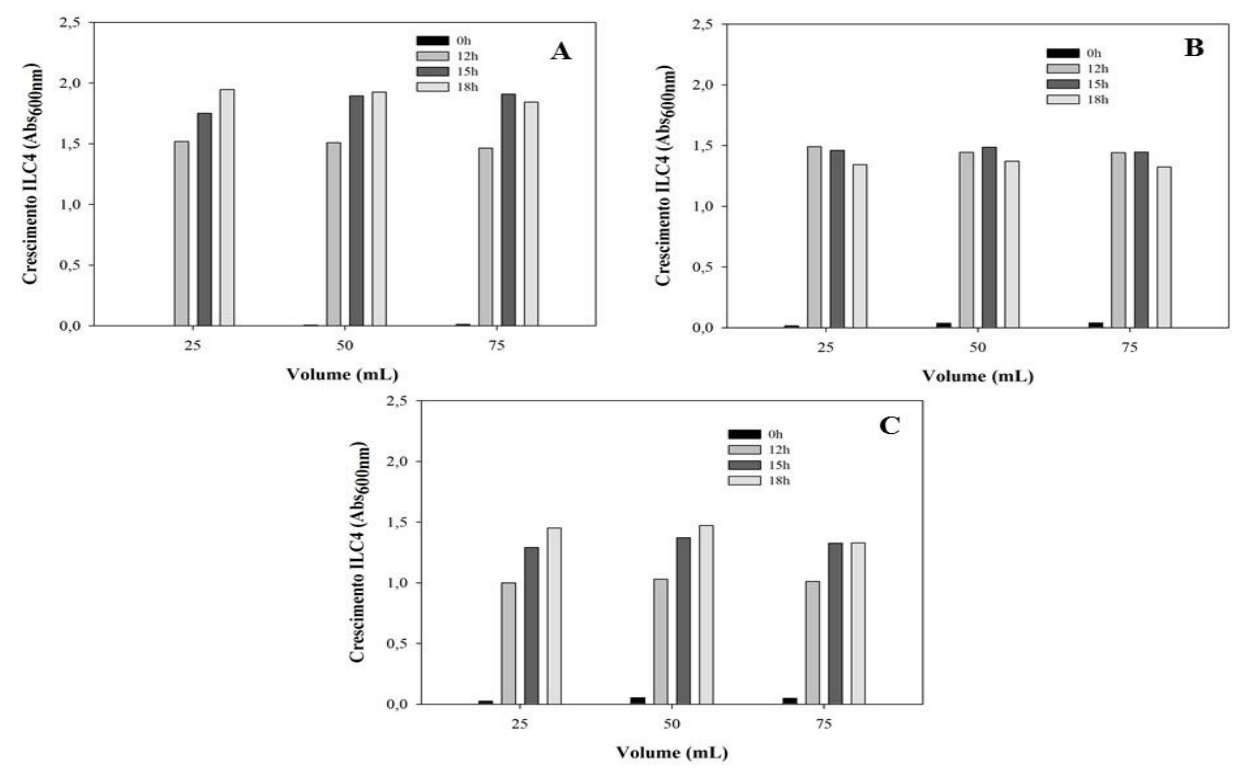

Figura 1 - Crescimento microbiano de ILC4 inoculado no pré-inóculo nas concentrações $1 \%$ (A);1,5\% (B) e 2\% (C) em diferentes proporções de aeração, por um período total de $18 \mathrm{~h}$.

Resultados similares foram observados para o isolado ILC23, onde foi verificado que as melhores condições para o preparo do pré-inóculo foram obtidos utilizando a concentração de $1 \%$ do isolado, proporção 1:5 por um período de $15 \mathrm{~h}$ (Figura 2).

Para ambos os isolados (ILC4 e ILC23), as concentrações de 1,5\% e $2 \%$ utilizadas para o preparo dos pré-inóculos não apresentaram crescimentos significativos, ou seja, valores próximos de 2,0 (D.0600nm). Este fato pode está relacionado à redução de nutrientes no meio de cultivo e acúmulo de produtos de degradação que agem inibindo o crescimento bacteriano.

Em um experimento realizado por SILVA (2015), resultados semelhantes foram encontrados, sendo a melhor proporção de aeração verificada na proporção de 1:5 por um período de $15 \mathrm{~h}$ de cultivo obtendo-se uma D.O. 600nm de 2,014. Apesar de ter sido verificada uma maior D.O. $600 \mathrm{~nm}$ na proporção de $1: 5$ cultivado por $18 \mathrm{~h}$, foi escolhido o tempo de $15 \mathrm{~h}$ de cultivo a fim de otimizar o tempo de crescimento.

Observa-se na Figura 3, que o isolado ILC4 cultivado na concentração de 1\%, nas proporções de 1:5, 2:5 e 3:5, apresentaram valores semelhantes quanto ao $\mathrm{pH}$ (pH em torno de 4,3 ), sendo o menor valor observado no tempo de $15 \mathrm{~h}$ de cultivo. Para as demais 
concentrações (1,5\% e $2 \%$ ), o menor valor foi observado no período de 18 h de cultivo para todas as proporções testadas.
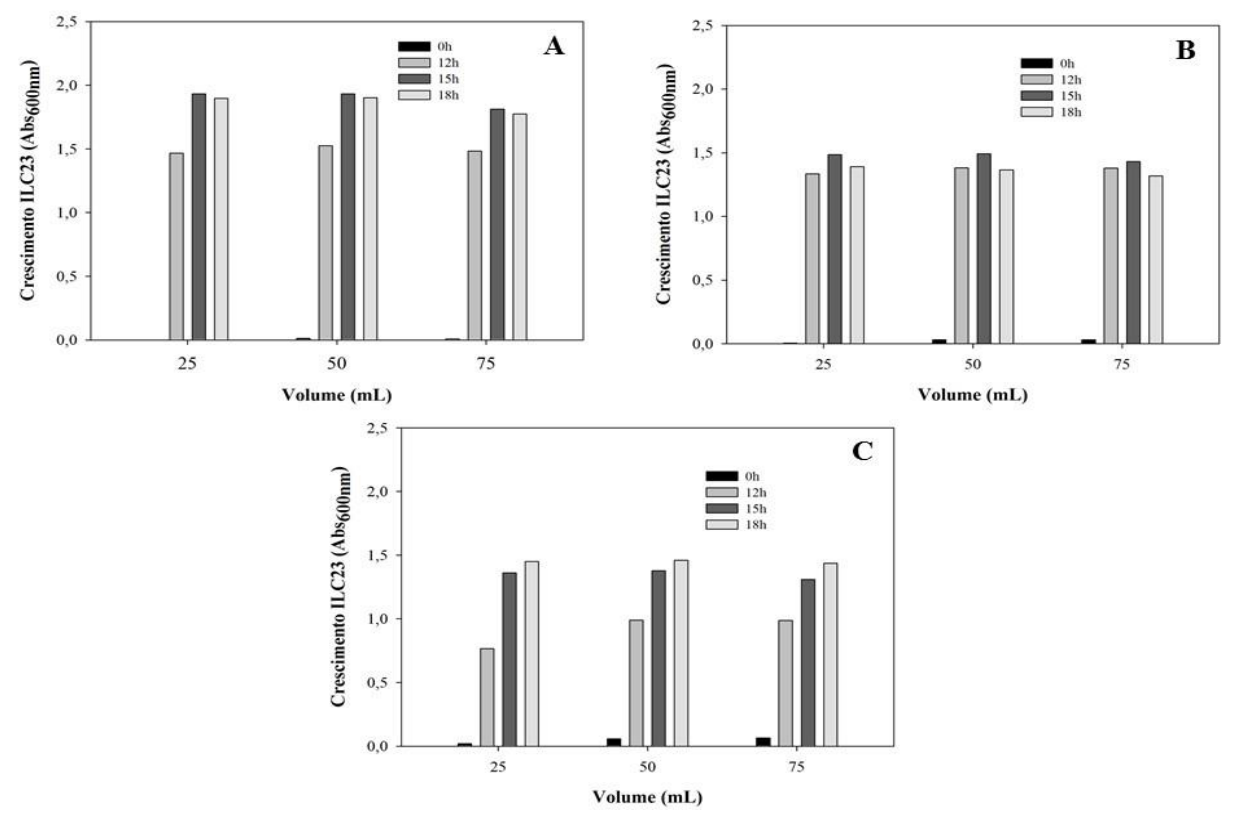

Figura 2 - Crescimento microbiano de ILC23 inoculado no pré-inóculo nas concentrações $1 \%$ (A);1,5\% (B) e 2\% (C) em diferentes proporções de aeração, por um período total de $18 \mathrm{~h}$.
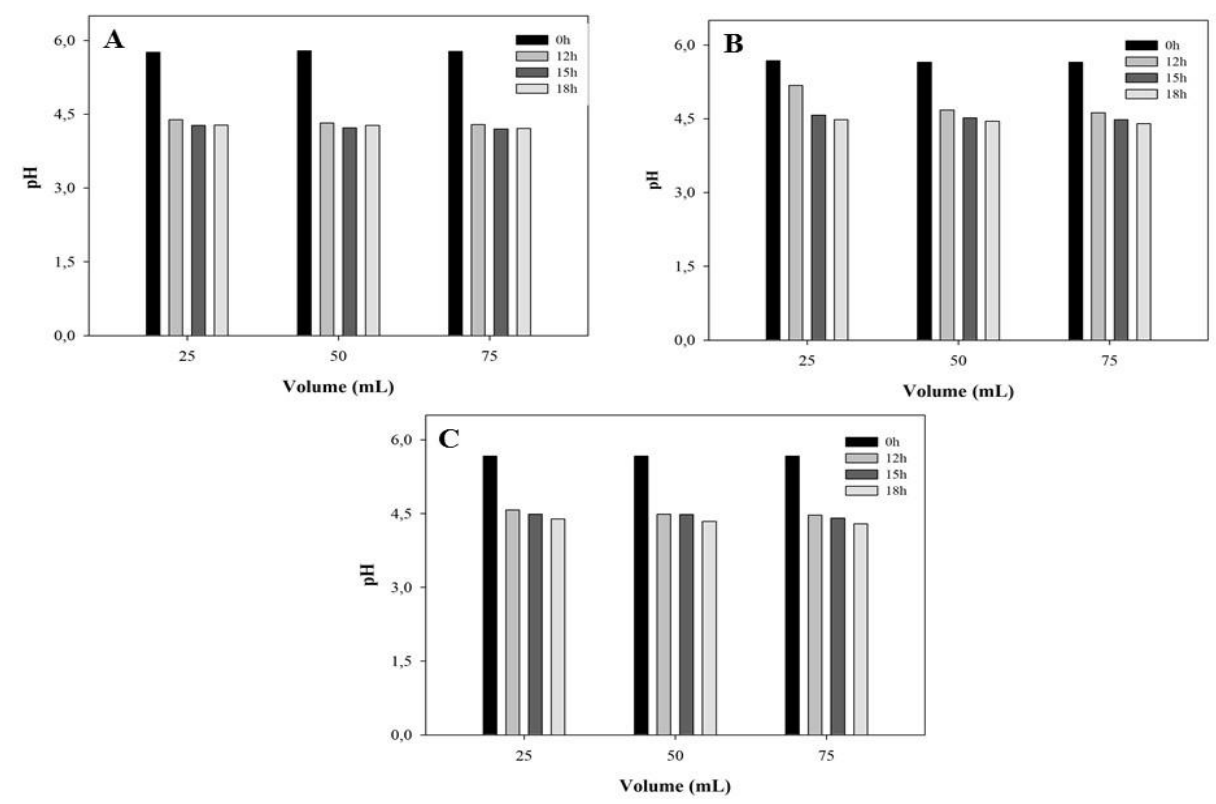

Figura 3 - Evolução do pH no pré-inóculo ILC 4 - 1\% (A); ILC4 - 1,5\% (B) e ILC4 $2 \%$ (C) em diferentes proporções de aeração, por um período total de 18 horas. 


\section{The Journal of Engineering and Exact Sciences - \\ JCEC}

ISSN: 2527-1075

Para o isolado ILC23, foi observado valores de $\mathrm{pH}$ semelhantes nas três proporções utilizadas $(1: 5,2: 5$ e 3:5) e na concentração de $1 \%$, onde o menor valor de $\mathrm{pH}$ obtido $(\mathrm{pH}=$ $4,3)$ foi no tempo de 15 horas. Nas concentrações de 1,5\% e $2 \%$ nas três proporções utilizadas $(1: 5,2: 5$ e $3: 5)$ o menor valor de $\mathrm{pH}(\mathrm{pH}=4,4)$ foi no tempo de 18 horas de cultivo (Figura $4)$.
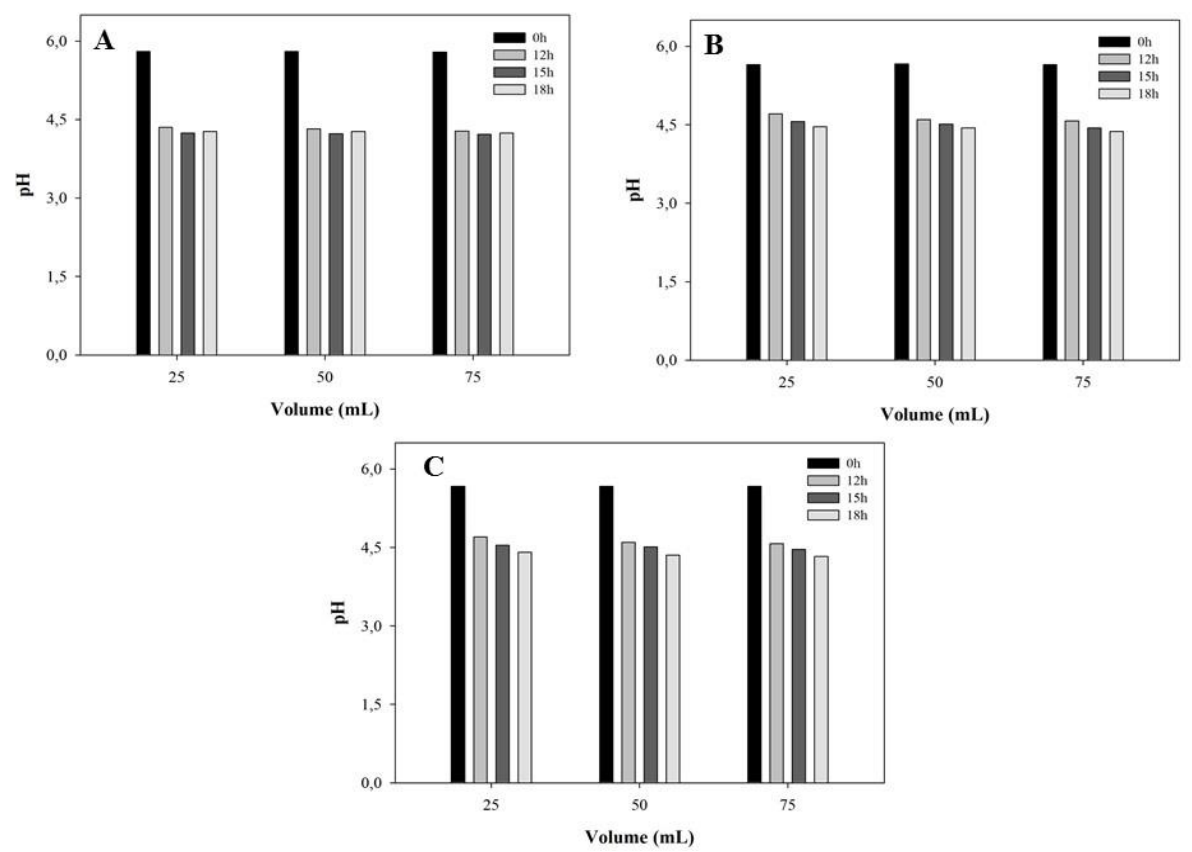

Figura 4 - Evolução do pH no pré-inóculo ILC23 - 1\% (A); ILC23 - 1,5\% (B) e ILC23 $2 \%$ (C) em diferentes proporções de aeração, por um período total de 18 horas.

A redução de $\mathrm{pH}$ está relacionada com o crescimento das bactérias ácido láticas no meio de cultivo, visto que há uma maior produção e liberação de ácido lático no meio proporcionando uma redução do $\mathrm{pH}$ e consequentemente aumento da acidez (SILVA, 2015). Estas curvas de crescimento e os valores de $\mathrm{pH}$ estão relacionados com o tempo de crescimento (h), podendo verificar as diferentes fases de crescimento (exponencial e estacionária) para os diferentes isolados analisados).

\section{CONCLUSÕES}

Ambos os isolados (ILC4 E ILC23) apresentam um melhor perfil de crescimento a uma concentração de $1 \%$ e a uma proporção de 1:5, apresentando valores próximos de 2,0, sendo este um valor estimado para a padronização de um pré-inóculo. Já quanto aos valores de $\mathrm{pH}$, tanto o isolado ILC4 quanto o ILC23, apresentaram um valor próximo a 4,5; nas concentração de $1,5 \%$ e $2 \%$ de pré-inóculo a um tempo de 12 horas de cultivo. Portanto, o preparo do préinóculo é uma etapa de grande importância para o cultivo de bactérias ácido láticas em meio líquido, pois favorece a adaptação da cultura as condições de crescimento em meio líquido, com isso ocorre também uma redução na fase lag de crescimento, sendo um fator muito importante nas etapas de produção de queijos e bebidas lácteas fermentadas. 


\section{REFERÊNCIAS}

HUERTAS, R. A. P. Bacterias acido lácticas: Papel funcional em los alimentos. Facultad de Ciencias Agropecuarias. p. 93-105, 2010.

LOPES, A. R. Produção de Ácido Lático por Lactobacillus em diferentes meios de cultivo. 2008. 75 p. Dissertação (Mestrado em Ciências Biológicas) - Instituto de Biociências da Universidade Estadual Paulista, Rio Claro, 2008.

SILVA, L. J. M. Isolamento e caracterização Bioquímica das Bactérias do ácido lático do Queijo São Jorge DOP. 2011. 135 p. Dissertação (Mestrado em Tecnologia e Segurança Alimentar) - Departamento de Ciências Agrárias da Universidade dos Açoares, Angra do Heroísmo, 2011.

SILVA, N.N. Avaliação das condições favoráveis para o crescimento e acidificação de bactérias ácido láticas isoladas do soro fermento de Queijos Minas Artesanal. 2015. 24 p. Trabalho de Conclusão de Curso (Bacharel em Ciência de Alimentos) Universidade Federal de Viçosa, Rio Paranaíba, MG, 2015. 